\section{КОММУНИКАЦИОННОЕ ПРОСТРАНСТВО КАК ОБЪЕКТ ПРАВОВОЙ ПОЛИТИКИ: ТЕОРЕТИЧЕСКИЕ ПРОБЛЕМЫ ФОРМИРОВАНИЯ ПРОСТРАНСТВЕННОГО ПОДХОДА}

\section{С. В. Тихонова}

доктор философских наук, профессор кафедры социальных коммуникаций, Саратовский государственный университет

E-mail: segedasv@yandex.ru

Введение. Статья посвящена обоснованию необходимости исследования трансформаций коммуникационного пространства при теоретическом анализе правовых аспектов построения информационного общества. Рассматриваются методологические аспекты исследования коммуникационного пространства в теории правовой политики, обсуждается использование пространственного подхода для этой цели. Обсуждение результатов. По мнению автора, теоретическая модель коммуникационного пространства позволит учитывать закономерности коммуникационной динамики, выявлять ориентиры и приоритеты социетальных трансформаций, вызванных детерминированным развитием информационно-коммуникационных технологий, сглаживать цифровой разрыв и будущие коммуникационные разрывы. Ее основой должна стать реляционная концепция пространства, позволяющая раскрывать сущность коммуникационного пространства через взаимодействие субъектов, что открывает новые перспективы для разработки моделей правового регулирования экстерриториальных пространств, порождаемых электронными сетями. Заключение. Делается вывод о фрагментарности развития пространственного подхода в юридической науке. Теоретические исследования правового пространства ориентированы на социально-философский пространственный подход и реляционную концепцию пространства. Прикладные исследования киберпространства (виртуального пространства) имеют субстанциальный характер. Барьером интеграции этих двух направлений является субстанционализм теоретико-правового учения о действии закона в пространстве, во времени и по кругу лиц, преодоление которого откроет новые перспективы для решения правовых проблем построения информационного общества.

Ключевые слова: юриспруденция, теория права, информационное право, правовая политика, коммуникационное пространство, пространственный подход, правовое пространство, киберпространство, виртуальное пространство.

\section{Введение}

Новые век ставит перед правовой политикой новые цели. Ключевым элементом современного социального развития стала эволюция коммуникационного пространства. Появление новых каналов коммуникации открыло перед человечеством новые возможности социальной организации, способные обеспечить возрастание степеней свободы и иной уровень реализации прав человека. Построение информационного общества, декларируемое сегодня многими государствами мира, призвано сделать достижения информационно-коммуникационного развития всеобщим достоянием.

Формирование доктрины информационного общества изначально отличалось многообразием и мозаичностью концепций. Выдвигавшиеся объяснительные модели акцентировали отдельные черты
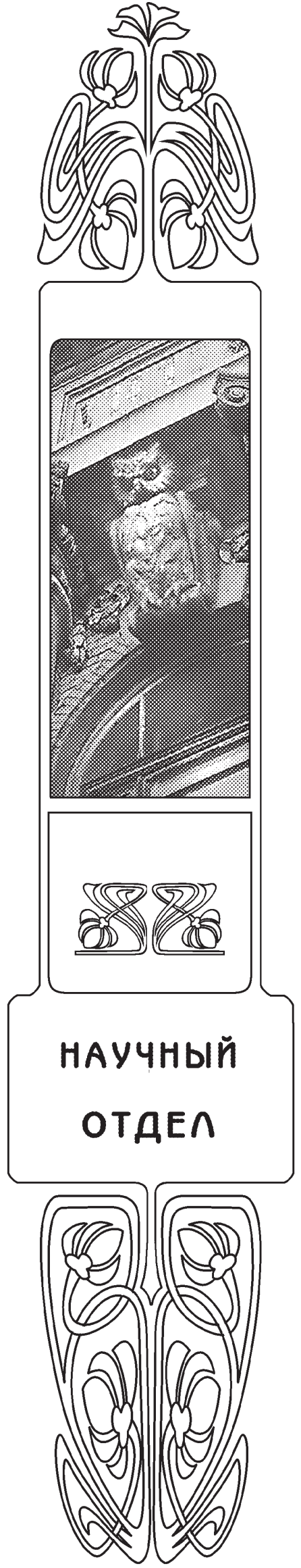
«нового мира», не всегда имевшие сущностный характер. Довольно быстро базовыми оказались понятия «информация» и «информатизация». Основное внимание исследователей в этой сфере было связано с новыми средствами коммуникации (электронными сетями), с социальными последствиями их распространения.

Вместе с тем эффективность правовой политики прямо зависит от системного и комплексного видения объекта. Полагаем, что теория правовой политики, генерирующая рекомендации для правотворческой практики, должна выработать теоретическую модель коммуникационного пространства, позволяющую оценивать направленность коммуникационной динамики, выявлять ориентиры и приоритеты вызванных развитием информационно-коммуникационных технологий социетальных трансформаций, затрагивающих общество в целом.

\section{Обсуждение результатов}

Коммуникационное пространство - одна из новых категориальных конструкций социальной философии, разрабатываемая для того, чтобы зафиксировать специфику социальных связей и отношений, развиваемых социальными субъектами. Коммуникационное пространство выступает особой формой бытия человека, в которой реализуются возможности организации социальных интеракций и социальных связей (отношений) при помощи каналов коммуникации. Базовыми элементами коммуникационного пространства являются коммуникационные структуры и коммуникационные системы. Первые представляют собой устойчивые комплексы коммуникационных цепей (например, коммуникационные службы, располагающие материально-техническими ресурсами и профессиональными кадрами), используемые коммуникантами, а коммуникационные системы - структурированные совокупности коммуникантов, смысловых сообщений, коммуникационных каналов и средства коммуникации (знаки и символы).

Центральный элемент коммуникационного пространства - коммуникационные каналы, поддерживающие социальные отношения. Каналами называют реальную или воображаемую линию связи (контакта), обеспечивающую движение сообщений от коммуникатора к реципиенту. Без этой линии коммуникация невозможна, благодаря ей осуществляется объективация смысла сообщений, идеального по своей природе. Канал обеспечивает средства для создания и восприятия сообщения (знаки, языки, коды, материальные носители сообщений, технические устройства), без которых люди не могли бы понимать друг друга. Представляя собой материальное измерение социальной коммуникации, канал осуществляет перемещение содержания (смысла) сообщения в социальном пространстве через физическую передачу сообщения в физическом пространственно-временном континууме. Исходными каналами являются естественные, использующие для передачи и приема сообщений возможности человеческого тела. В процессе исторического развития появляются искусственные каналы, обеспечивающие дистантную, опосредованную, коммуникацию благодаря применению орудий и технических устройств. Именно появление новых каналов является движущей силой развития коммуникационного пространства.

От появления первых идей работы искусственного канала до его массового распространения может проходить несколько сотен лет. Но в условиях научно-технического прогресса этот срок сокращается до четверти столетия. Появление новых форм коммуникации, основанных на распространившихся каналах, является коммуникационной революцией, поскольку инициирует массовые социальные изменения и усиление социальной динамики. Дистантная коммуникация предоставляет реципиентам доступ к таким типам информации, которые ранее для них были закрыты, кроме того, появление новых видов дистантной коммуникации усиливает дифференциацию и специализацию социальной информации.

Развитие технологических каналов в новейшее время привело невероятному усложнению коммуникационного пространства и социальных систем в целом. Часто хронологическое рассмотрение, стадиально анализирующее появление прессы, радио, телевидения, Интернета, порождает иллюзию, что изобретаемые каналы коммуникации замещают друг друга. Тем не менее, изобретение письменности не отменяет устной речи и не уменьшает ее социального значения, так же как изобретение телевидения не приводит к забвению письма.

Существование коммуникационных каналов комплементарно, изобретение и распространение новых средств коммуникации приводит к расширению коммуникационного пространства, появлению в нем специфических сегментов, включающих в себя характерные коммуникационные системы и структуры. В этих сегментах концентрируются трансляция и хранение конкретных видов социальной информации, имеющих разное значение для процессов социального воспроизводства и управления. Однако распределение информации в сегментах не является жестким, она дублируется. Взаимодействие сегментов часто приобретает характер синергизма, взаимного усиления их собственных эффектов. 
Расширение коммуникационного пространства меняет конфигурацию пространства социального, увеличивает рост социальных интеракций и число взаимодействующих субъектов. Развитие коммуникационного пространства прошло четыре этапа, сопряженных с появлением новых средств коммуникации: этап устной коммуникации, этап письменной коммуникации, этап массовой коммуникации и современная коммуникационная революция. Соответственно, в современном коммуникационном пространстве могут быть выделены сегменты (зоны) письменной коммуникации, массовой коммуникации и электронной коммуникации. Важно отметить, что электронная коммуникация обеспечивает интеграцию предшествующих форм и видов, предоставляя пользователям самостоятельно определять круг реципиентов и режим общения (в реальном или отложенном времени). При этом она влияет на предшествовавшие каналы, вызывая к жизни интегрированные медиа, СМИ на электронной платформе, цифровое телевидение, изменяя приспособления для письма на клавиатуру и голосовое управление. В современных условиях каналы коммуникации являются не столько новой средой социальных интеракций, они трансформируются в средства установления общественных отношений.

Процессы глобализации привели к объединению коммуникационных пространств отдельных стран в единое целое. Таким образом, сегодня национальное коммуникационное пространство - фрагмент планетарного, в его рамках осуществляются коммуникации самых различных видов, причем исключительный характер имеют горизонтальные коммуникации, существенный объем которых имеет транснациональный характер. Построение информационного общества требует от субъектов правовой политики системного стратегического мышления, учитывающего как статику, так и динамику коммуникационного пространства. Правовая политика в сфере техногенных основ цивилизации должна способствовать научно-техническому прогрессу, сглаживая его негативные моменты. Данный тезис верен и в отношении коммуникационного пространства. Однако его антропогенное измерение усиливает слабую предсказуемость последствий технических прорывов в этой области. Таким образом, возрастает значение теоретического осмысления коммуникационного пространства как объекта правовой политики.

По нашему мнению, эта задача может быть решена на основе применения пространственного подхода, который активно разрабатывается в последние годы в социальном знании. Простран- ственный поворот в социальной философии позволил переосмыслить социальную реальность в терминах «пространство», «ресурсы», «капитал», «структурация», показать многомерность социальной материи, сложность ее символических измерений. Пространственность человеческого бытия определяет структурирование человеком его социально-политических и культурных практик. Социальное пространство является антропогенным, т.е. возникает в процессе взаимодействия человека и объектов окружающего мира, в ходе человеческой деятельности, раскрывается через территориальную прикрепленность к физическому пространству и конструируется в соответствии с принципами организации человеческой телесности. Множественность полей, входящих в структуру социального пространства, является единым целым благодаря социальной коммуникации. Коммуникация как основополагающая форма социальных взаимодействий играет фундаментальную роль в процессе интеграции и структурирования антропогенных пространств. Исследования в области социологии пространства, антропологии пространства, политологии пространства тесно связаны с предметным полем коммуникативистики. Вместе они формируют образ нелинейной динамики социальной жизни, заменяя простые антропоморфные метафоры наивного органицизма сложными теоретическими моделями, отражающими многообразие социальных интеракций, осуществляемых различными социальными субъектами.

В юридической науке исследования пространства осуществляются в рамках теории права и в рамках интернет-права. Эти два направления практически не связаны между собой и разнесены по теоретическому и эмпирическому «этажам» науки. Первое, теоретическое, направление связано с понятием «правовое пространство», которое в последние годы в правовой теории трансформируется из публицистической метафоры в научную категорию [1, с. 94]. Как отмечает А. А. Федорченко, правовое пространство выступает как совокупность правовых отношений, выражающих координацию субъектов права, материальных объектов, их расположение относительно друг друга, выраженную в виде взаимных правовых притязаний, возникающих на основе взаимных прав и обязанностей [2, c. 46]. Так понятое правовое пространство оказывается реальной моделью информационно-коммуникативной среды, где взаимное расположение соответствующих элементов (субъекты, объекты, время, территория, действия, знаки, символы, события и т.д.) на основе правовых смыслов создает необходимый объем (характер) правовой деятельности. Исследования правового про- 
странства практически сразу обеспечивали соотнесение с существующим пространственным подходом в теоретическом социальном знании, будучи ориентированными на философские достижения в этой области [3].

Второе, прикладное, направление формируется в информационном праве. Общие рамки его формирования заданы категориальной разработкой понятий «киберпространство», «виртуальное пространство» и прочих категорий, используемых для обозначения социальной среды Интернета. Часто эти понятия получали легальное закрепление в международных документах до теоретической научной разработки, например, Верховный суд США еще в прошлом веке определил киберпространство как «уникальный носитель, известный его пользователям как киберпространство, не находящийся на определенной территории, но доступный каждому в любой точке мира» [4].

Одним из первых в отечественной юридической науке термин «кибернетическое пространство» начал использовать Д. В. Грибанов. По его мнению, под этим термином нужно понимать совокупность общественных отношений, возникающих в процессе использования функционирующей электронной компьютерной сети, складывающихся по поводу информации, обрабатываемой с помощью ЭВМ и услуг информационного характера, предоставляемых с помощью ЭВМ и средств связи компьютерной сети [5, с. 12]. Исследователь подчеркивает, что кибернетическое пространство как явление включает в себя две смысловые составляющие: техническую и информационную. Из них ведущее место принадлежит информационной, поскольку организация движения информации является целью существования кибернетического пространства, его технические элементы служат средствами достижения указанной цели.

Далее этот термин анализирует И. М. Рассолов, сократив его, под влиянием английской традиции словоупотребления, как «киберпространство». Киберпространство в его интерпретации - это сфера социальной деятельности, связанная с оборотом информации во Всемирной информационной паутине, а также в других информационно-коммуникационных сетях (региональных, опорных, ведомственных, корпоративных) [6, с. 6]. Подчеркивая сложность киберпространства, автор акцентирует значение социальной стороны киберпространства, в рамках которой киберпространство есть совокупность общественных отношений, возникающих в процессе использования Интернета и других сетей, складывающихся по поводу присутствующей в этих сетях информации, обрабатываемой при помощи ЭВМ. Показательно, что термины «виртуальное пространство» и «киберпространство» И. М. Рассолов считает синонимами. Не отрицая разных теоретических и семантических источников этих терминов, отметим, что функционально они выполняют одну и ту же задачу - описывают социальную реальность, формирующуюся в процессе использования компьютерных сетей. Так, например, Н. Н. Телешина характеризует виртуальное пространство как «область технических, технологических и социальных отношений, возникающих, изменяющихся и прекращающихся в процессе использования компьютерной или иной электронной технической сети по поводу информации, информационных ресурсов, информационных услуг и средств связи» [7, с. 9].

Н. Н. Федосеева продолжает исследовательскую логику И. М. Рассолова и определяет виртуальное пространство как среду, возникающую в процессе использования компьютерной или иной электронной сети, в которой возникают информационные отношения по поводу информации и информационных ресурсов, преимущественно обрабатываемых с помощью электронных устройств, услуг информационного характера, преимущественно предоставляемых с помощью электронных устройств и средств связи технологической сети. Сущность виртуального пространства состоит в том, что оно представляет собой совокупность технических, технологических и социальных отношений [8, с. 11].

Н. Н. Федосеева приходит к выводу, что пространство - это состояние материи, характеризуемое наличием протяженности и способное что-либо вмещать [8, с. 49]. Аналогичную позицию демонстрирует и И. М. Рассолов [6]. Однако в философской традиции пространство определяется как форма бытия материи, как состояние материи обычно определяют поле, которое наряду с веществом и вакуумом рассматривают как виды материи. Акцентируя способность вмещать что-либо как базовую характеристику пространства, исследователи развивают де-факто субстанциальную концепцию пространства, характерную для классической механики. Еще И. Ньютон развивал идею пространства как вместилища, понимая под ним пустое вместилище любых возможных тел, абсолютное и не зависящее ни от тел, которые в нем находятся, ни от процессов, которые в нем происходят. Субстанциальная концепция пространства интуитивно близка человеческому мышлению, но не совпадает с современной научной картиной мира.

Пространство, наряду со временем, относится к фундаментальным понятиям культуры [9, c. 3], содержание которых подвержено изменению в контексте развития представлений об окру- 
жающем мире. Современная физика выработала реляционную концепцию пространства и времени, в которой они рассматриваются как системы отношений, образуемые взаимодействующими материальными объектами. Вне таких систем пространство и время не существуют, поскольку выступают как общие формы координации материальных объектов и их состояний, что позволяет говорить о зависимости свойств пространства и времени от характера взаимодействия материальных систем [9, 10].

Пространство, как и время, будучи обусловленным движением материи, может образовывать множество пространственных форм [11] в соответствии с тезисом о существовании в мире неисчерпаемого множества видов материи и форм движения. В качестве методологической позиции реляционная концепция пространства и времени, реализуемая применительно к социальной форме движения материи, позволяет фиксировать и рассматривать пространственные структуры социального бытия человека в качестве пространств, возникающих и функционирующих в процессе деятельности человека (коммуникационное, социальное, жизненное, историческое, правовое и т.п.). Взаимодействия и связи этих пространств складываются по собственным закономерностям, их характер неслучаен.

В информационном праве виртуальное пространство (киберпространство) уже почти традиционно рассматривается как часть информационного пространства. Реляционная модель позволила бы соотнести его с коммуникационным пространством, что дало бы возможность не игнорировать техногенный сегмент информационного пространства (информация циркулирует в том числе и по естественным каналам коммуникации, обладающим своей спецификой). Она позволила бы, исходя из тезиса о единстве коммуникационного пространства, учитывать те изменения, которые происходят с более традиционными каналами (например, развитие мобильной телефонии, появление электронных «зеркал» у традиционных СМИ, отмирание проводного телеграфа и т.п.) и дифференцировать цели и задачи правовой политики в этой сфере.

Особо необходимо отметить перспективы исследования самого Интернета. Последний захватывает исследовательское внимание в силу своей новизны, и этот захват искажает его масштабы. Конвергенция технологий приведет к появлению новых медиа, а значит, изучение только Интернета (все оговорки о том, что к виртуальному пространству относятся «и другие сети», не отменяют единичности источника эмпирических данных) очень быстро превратится в попытку исследования головы в надежде познать закономерности человеческой анатомии. Интернет также меняется. Его история знает забвение некогда популярных сервисов. Кроме того, изменения могут носить и глобальные характер - так, социальные сети вызвали социализацию Интернета, прежде ориентированного на анонимное общение. Интернет будет продолжать меняться, что детерминирует значимость динамических теоретических концепций.

Кроме того, реляционная модель раскрывает сущность коммуникационного пространства через взаимодействие субъектов, что важно для понимания и регулирования сферы, определяемой через «экстерриториальность». Элиминация принципа территориальности, характерного для предыдущих форм коммуникации, свойственна интернет-отношениям. Но субстанциальная модель пространства имплицитно предполагает метафору границ, а значит, не соответствует своему объекту. Тем не менее, ее существование имеет практическое значение. Она обеспечивает решение проблемы юрисдикций, исходя из сложившегося учения о действии нормативноправовых актов во времени, пространстве и по кругу лиц. И если Интернет можно трактовать как пространство с нарушенным принципом территориальности, то нормативно-правовой акт остается сформулированным в рамках территориального каркаса понятий, априорно субстанциального. Таким образом, формирование пространственного подхода к коммуникационному пространству в теории правовой политики возможно не через прямое соотнесение теоретических и прикладных исследований пространства в юридической науке, а через модернизацию учения о действии нормативно-правовых актов.

\section{Заключение}

В условиях информационного общества коммуникационное пространство становится значимым объектом правовой политики, его правовое регулирование сможет обеспечить равномерность и устойчивость цивилизационного развития, сгладить цифровой разрыв и новые, грядущие коммуникационные разрывы, снижающие широту человеческой свободы и препятствующие полной реализации прав человека в новых техногенных условиях. Формирование теоретической модели коммуникационного пространства в теории правовой политики возможно на базе пространственного подхода. Последний активно развивается в социальном знании, обеспечивая научную картину нелинейного и многомерного социального развития. Формирование основ пространственного подхода осуществляется в теоретических 
и прикладных исследованиях в юридической науке. Первые представлены исследованиями правового пространства и соотнесены с социально-философским пространственным подходом. Вторые развиваются автономно и развивают субстанциальную модель пространства. Основным барьером на пути их интеграции на платформе реляционной модели пространства является субстанционализм учения о действии закона в пространстве, во времени и по кругу лиц.

\section{Список литературы}

1. Козюк М. Н. Правовое пространство и правовое поле // Науч. вестн. Волгоград. акад. гос. службы. Сер. Юриспруденция. 2010. № 2. С. 94-99.

2. Федорченко А. А. Правовое пространство : основные подходы // Новый юридический журнал. 2012. № 3. C. 49-51.

3. Зинков Е. Г. Термин пространство в теории права // Общество и право. 2011. № 4. С. 13-19.

4. Darrel Menthe. Jurisdiction in Cyberspace : A Theory of International Spaces // 4 MICH.TELECOMM.TECH.L.
REV. 69 (1998). URL: http://www.mttlr.org/volfour/ menthe.pdf (дата обращения: 20.05.2014).

5. Грибанов Д. В. Правовое регулирование кибернетического пространства как совокупности информационных отношений : автореф. дис. ... канд. юрид. наук. Екатеринбург, 2003. 23 с.

6. Рассолов И. М. Право и Интернет. Теоретические проблемы. 2-е изд., доп. М. : Норма, 2009. 384 с.

7. Телешина Н. Н. Виртуальное пространство как объект контрольной деятельности государства : автореф. дис. ... канд. юрид. наук. Владимир, 2011. 29 с.

8. Федосеева (Телешина) Н. Н. Контроль виртуального пространства как направление деятельности Российского государства. Муром : Изд.-полиграф. центр МИ ВлГУ, 2010. 206 с.

9. Ахундов М. Д. Концепции пространства и времени : Истоки, эволюция, перспективы. М. : Наука, 1982. $223 \mathrm{c}$.

10. Свидерский В. И. Пространство и время. М. : Госполитиздат, $1958.200 \mathrm{c}$.

11. Потемкин В. К., Симанов А. Л. Пространство в структуре мира. Новосибирск : Наука (Сиб. отд-ние), 1990. 177 [2] c.

\title{
Communication Space as Object of Legal Policy: Theoretical Problems of Spatial Approachformation
}

\author{
S. V. Tikhonova \\ Saratov State University, \\ 83, Astrakhanskaya, Saratov, 410012, Russia \\ E-mail: segedasv@yandex.ru
}

Introduction. The article deals with methodological aspects of research of communication space in the theory of legal policy, it also discusses the application of spatial approach for this purpose. Discussion of results. In our opinion, the theoretical model of communication space allows to take into account the patterns of communication dynamics, to identify the objectives and priorities of the societal transformations, to mitigate the digital divide and the future communication divides. Conclution. The author comes to the conclusion that jurisprudence spatial approach is fragmentary. Theoretical researches of legal space are focused on the social and philosophical spatial approach and the relational concept of space. Empirical researches of a cyberspace (virtual space) have substantial character. Their integration barrier is the substantivism of the theoretical legal doctrine about law action in space, in time and around persons.

Key words: law, law theory, information law, legal policy, communication space, spatial approach, law space, cyberspace, virtual space.

\section{References}

1. Kozjuk M. N. Pravovoe prostranstvo i pravovoe pole [Law space and law field]. Nauchnyj vestnik Volgogradskoj akademii gosudarstvennoj sluzhby. Ser. Jurisprudencija [Volgograd State Service Academe Science Bulletin], 2010, no. 2, pp. 94-99.

2. Fedorchenko A. A. Pravovoe prostranstvo: osnovnye podhody [Law space: the main approaches]. Novyj juridicheskij zhurnal [New juridical journal], 2012, no. 3, pp. 49-51.

3. Zinkov E. G. Termin prostranstvo v teorii prava [Ehe term space in the theory of law]. Obshhestvo i pravo [Society and Law], 2011, no. 4, pp. 13-19.

4. Darrel Menthe. Jurisdiction in Cyberspace: A Theory of International Spaces. 4 MICH.TELECOMM. TECH.L.REV. 69 (1998). Available at: http://www.mttlr. org/volfour/menthe.pdf (accessed 20 May 2014).
5. Gribanov D. V. Pravovoe regulirovanie kiberneticheskogo prostranstva kak sovokupnosti informacionnyh otnoshenij: avtoref. dis. ... kand. jurid. nauk [The Law Regulation of the Cyberspace as the Complex of Information Relations. Cand. law sci. thesis diss.]. Ekaterinburg, 2003. 23 p.

6. Rassolov I. M. Pravo i Internet. Teoreticheskie problemy [Law and Internet. Theoretical problems. 2nd ed.]. Moscow, 2009. 384 p.

7. Teleshina N. N. Virtualnoe prostranstvo kak objekt kontrol'noj dejatelnosti gosudarstva: avtoref. dis. ... kand. jurid. nauk [Virtual space as an object of control activities of the state. Cand law sci. thesis diss.]. Vladimir, 2011. 29 p.

8. Fedoseeva (Teleshina) N. N. Kontrol' virtual'nogo prostranstva kak napravlenie dejatel'nosti rossijskogo gosudarstva [Virtual space control as the activity of the Russian state]. Murom, 2010. 206 p. 
9. Ahundov M. D. Koncepcii prostranstva i vremeni: Istoki, jevoljucija, perspektivy [The conceptions of space and time: origins, evolutions, perspectives]. Moscow, 1982. 223 p.
10. Sviderskij V. I. Prostranstvo i vremja [Space and time]. Moscow, 1958. 200 p.

11. Potemkin V. K., Simanov A. L. Prostranstvo v strukture mira [Space in the world structure]. Novosibirsk, 1990. 177 [2] p. 